http://dx.doi.org/10.5050/KSNVE.2012.22.6.542

$$
\text { 입력성형기를 이용한 회전 유연보의 조종 및 진동제어 }
$$

\title{
Maneuvering and Active Vibration Control of Slewing Flexible Beam Using Input Shaper
}

\author{
곽 문 규†.양 동 호*. 이 재 하* \\ Moon K. Kwak, Dong-Ho Yang and Jae-Ha Lee \\ (2012년 3월 14일 접수 ; 2012년 4월 16일 심사완료)
}

Key Words : Slewing Beam(회전보), Maneuvering(조종), Vibration Control(진동제어), Input Shaping(입력 성형)

\begin{abstract}
This research is concerned with the derivation of equations of motion for a slewing beam and the application of input shaper to the bang-bang control to achieve vibration suppression. When a uniform beam with a tip mass rotates about the axis perpendicular to the undeformed beam's longitudinal axis, it experiences inertial loading. Hence, the beam vibrates. In this paper, we used the input shaper for the maneuvering control to suppress vibrations. The maneuvering control which can achieve a minimum-time control is a bang-bang control. The input-shaped bang-bang maneuvering is used to suppress vibrations both theoretically and experimentally. The slewing beam experiment is not an easy subject because of the inherent damping existing inside the rotor. We propose the use of a negative damping to eliminate the rotor damping. Numerical and experimental results show that the input-shaper can be effectively used for the vibration suppression of a slewing beam.
\end{abstract}

\section{1. 서 론}

회전구조물에 능동진동제어 문제가 본격적으로 논의 되기 시작한 것은 인공위성과 우주왕복선의 개발과 더불어 우주 개발이 이루어지던 1970년대부 터라고 볼 수 있다 ${ }^{(1,2)}$. 특히, 우주 공간상에서 인공 위성의 위치를 바꾸어야 하는 경우에 인공위성 허 브에 부착된 경량 구조물에 진동이 발생할 수 밖에 없다. 이와 같은 우주구조물의 자세 제어에는 각도

† 교신저자; 정회원, 동국대학교 기계로봇에너지공학과 E-mail :kwakm@dongguk.edu

Tel : (02)2260-3705, Fax : (02)2263-9379

* 정회원, 동국대학교 대학원

\# 이 논문의 일부는 2012년 춘계 소음진동 학술대회에서 발표되었음.
를 제어하는 위치제어와 이동 중과 이동 후에 발생 하는 진동의 제어를 포함하고 있다. 경량 우주구조 물의 진동제어는 압전감지기와 작동기를 이용해 진 동을 능동적으로 제어하는 방법 ${ }^{(3)}$ 과 입력성형기 (input shaper)를 이용해 조종으로부터 발생하는 잔 류진동을 억제하는 방법(4,5) 등이 제안되어 있다.

우주구조물과 같은 구조물의 회전(slewing)을 연 구하기 위해 많은 연구자들(1 3,6,7)이 보의 회전에 대 한 동적모델을 연구해 왔다. 이 연구에서는 끝단에 집중질량이 매달려 있으며 다른 단의 축이 모터 로 터에 연결된 보구조물에 대해 가정모드법을 이용해 동적 모델을 유도하였다. 동적 모델로부터 알 수 있 듯이 강체 회전 운동과 보의 진동은 관성적으로 연 성되어 있다.

우주공간 상에서는 우주구조물의 회전에 저항하는 마찰력이 존재하지 않지만 지상에서 구조물의 회전 
을 시도하기 위해서는 모터를 사용하기 때문에 회전 에 저항하는 마찰력이 존재한다. 따라서 bang-bang 제어와 같은 최소시간 제어의 유효성을 지상에서 입증하기 어렵다. 보구조물의 회전에 관한 실험을 Kwak and $\mathrm{Nam}^{(3)}$ 이 시도하였는데 기어 모터의 특 성으로 인해 이론에서 나타나는 강체 회전 운동과 유연보의 진동이 연성되는 효과를 관찰할 수 없었 다. 이 연구의 실험에서는 기어에 의한 마찰력을 없 애기 위해 BLDC 모터를 사용하고 피드백 제어에 음의 감쇠효과를 더해 회전에 대한 저항을 제거하 였다. 이를 통해 보의 회전과 진동이 연성된 현상을 실험에서 관찰할 수 있도록 만들었다.

앞에서 설명한 바와 같이 경량 우주구조물의 자 세 제어는 진동을 유발한다. 이 연구에서는 입력성 형기 ${ }^{(4,7,8)}$ 를 이용해 진동을 억제하는 방법을 토의한 다. 특히, Bang-bang 제어에 입력성형기를 적용해 회전하는 우주구조물의 진동 억제에 대한 연구를 수행하였다. 입력성형된 bang-bang 제어의 효과를 실험으로 입증한 예가 없는데, 이 실험에서는 이를 시도하였다.

이 연구에서 유도한 이론 모델에 대한 수치 모사 결과와 실험 결과는 유사한 형태를 보여주어 이 연 구에서 도출한 결과들이 타당함을 보여준다.

\section{Slewing 보의 동적 모델링}

먼저 Fig. 1과 같이 끝단에 집중질량이 매달려 있 고 회전축은 모터의 로터에 연결된 유연보를 고려 해보자. 보는 Euler-Bernoulli 보로 가정하고 보의 회전에 대한 마찰력은 없다고 가정한다.

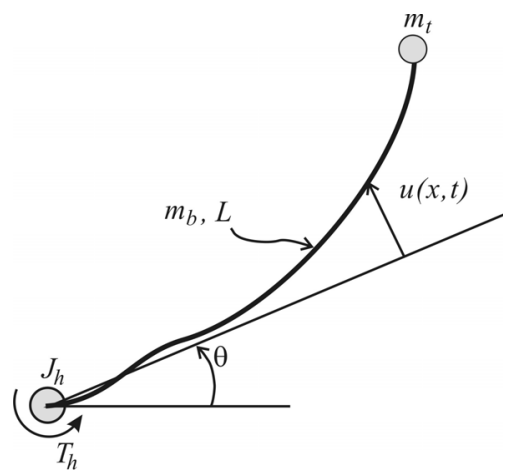

Fig. 1 Experimental setup for slewing
여기서 $\theta$ 는 수평축에 대한 보의 기준축의 회전 각을 나타내며, $u(x, t)$ 는 $x$ 에서의 굽힘 변위를 나 타낸다. $m_{b}$ 는 보의 질량, $L$ 은 보의 길이, $m_{t}$ 는 끝 단에 부착된 질량, $J_{h}$ 는 모터 로터의 회전질량관성 모멘트, $T_{h}$ 는 회전을 위해 로터에 적용된 토크를 나타낸다. 수치모사를 위해 가정모드법을 사용하면 굽힘 변위를 다음과 같이 쓸 수 있다.

$$
u(x, t)=\boldsymbol{\Phi}(x) \mathbf{q}(t)
$$

여기서 $\boldsymbol{\Phi}(x)=\left[\phi_{1}(x) \phi_{2}(x) \cdots \phi_{n}(x)\right]$ 는 허용함수 로 이루어진 $1 \times n$ 행렬이며, $\mathbf{q}(t)=\left[\begin{array}{ll}q_{1}(t) & q_{2}(t)\end{array}\right.$ $\left.\cdots q_{n}(t)\right]^{\mathrm{T}}$ 는 일반좌표계로 이루어진 $n \times 1$ 벡터이다. 이와 같은 이산화 기법을 적용하면 운동에너지가 다음과 같이 유도된다.

$$
T=\frac{1}{2} J_{t} \dot{\theta}^{2}+\dot{\theta} \tilde{\boldsymbol{\Phi}}_{t} \dot{\mathbf{q}}+\dot{\mathbf{q}}^{\mathrm{T}} \mathbf{M}_{t} \dot{\mathbf{q}}
$$

여기서

$$
\begin{aligned}
& J_{t}=J_{h}+\frac{1}{3} m_{b} L^{2}+m_{t} L^{2}, \\
& \tilde{\boldsymbol{\Phi}}_{t}=\tilde{\boldsymbol{\Phi}}_{b}+m_{t} L \boldsymbol{\Phi}(L), \\
& \mathbf{M}_{t}=\mathbf{M}_{b}+m_{t} \boldsymbol{\Phi}^{\mathrm{T}}(L) \boldsymbol{\Phi}(L)
\end{aligned}
$$

여기서

$$
\begin{aligned}
& \mathbf{M}_{b}=m_{b} \int_{0}^{1} \boldsymbol{\Phi}^{\mathrm{T}} \boldsymbol{\Phi} d \xi \\
& \tilde{\boldsymbol{\Phi}}_{b}=m_{b} L \int_{0}^{1} \xi \boldsymbol{\Phi} d \xi
\end{aligned}
$$

$\xi=x / L$ 이 무차원 변수로 활용되었다. 보의 탄 성에너지는 다음과 같이 표현된다.

$$
V=\frac{1}{2} \mathbf{q}^{\mathrm{T}} \mathbf{K}_{b} \mathbf{q}
$$

여기서

$$
\mathbf{K}_{b}=\frac{E I}{L^{3}} \int_{0}^{1} \boldsymbol{\Phi}^{\prime \prime \mathrm{T}} \boldsymbol{\Phi}^{\prime \prime} d \xi
$$

운동에너지 식 (2)와 탄성에너지 식 (5), 그리고 
보에 대한 감쇠행렬을 가정하면 다음과 같은 운동 방정식이 유도된다.

$$
\begin{aligned}
& J_{t} \ddot{\theta}+\tilde{\boldsymbol{\Phi}}_{t} \ddot{\mathbf{q}}=T_{h} \\
& \tilde{\boldsymbol{\Phi}}_{t}^{\mathrm{T}} \ddot{\theta}+\mathbf{M}_{t} \ddot{\mathbf{q}}+\mathbf{C}_{b} \dot{\mathbf{q}}+\mathbf{K}_{b} \mathbf{q}=0
\end{aligned}
$$

여기서 감쇠 행렬, $\mathbf{C}_{b}$ 가 도입되었다. 수치계산에 서는 비례감쇠, 즉 $\mathbf{C}_{b}=\alpha \mathbf{M}_{t}+\beta \mathbf{K}_{b}$ 가 사용되었 다. 식 (7)을 살펴보면 회전각, $\theta$ 와 일반변위벡터, $\mathbf{q}$ 가 관성적으로 연성되어 있음을 알 수 있다. 기어 모터를 사용하는 경우에 기어 내부의 마찰 력으로 인해 식 (7a)에서 나타나는 것과 같은 연 성은 나타나지 않는다. 따라서 실험으로 이런 연 성을 관찰하기 위해서는 마찰력이 거의 없는 모 터를 사용해야 하는데 이 연구에서는 BLDC 모 터와 음의 감쇠계수를 피드백 제어에 적용해 구 현하였다.

지능구조물의 경우에는 식 $(7 \mathrm{~b})$ 에 압전작동기에 의한 외력을 포함시켜야 하는데 이를 통해서도 진동을 억제할 수 있다. 그러나 이 연구에서는 모 터 토크, $T_{h}$ 에 입력성형기를 적용해 조종과 진동 제어를 동시에 수행하는 방법을 연구하였다.

\section{3. 입력 성형된 Bang-bang 제어}

식 (7a)에서 탄성진동항을 무시하고 강체 운동만 을 고려하면 다음과 같은 식이 유도된다.

$$
J_{t} \ddot{\theta}=T_{h}
$$

이와 같은 강체의 정지출발-정지멈춤(rest-to-rest) 위치 제어를 가장 빠른 시간내에 이룩할 수 있는 제어는 최소 시간 제어(minimum time control)이다. 최소시간 제어법칙에 의해 유도된 제어기는 bangbang 제어기인데 다음과 같이 표현된다.

$$
T_{h}=\left\{\begin{array}{cc}
T_{m} & 0<t<t_{\text {off }} \\
-T_{m} & t_{o f f}<t<2 t_{\text {off }} \\
0 & \text { otherwise }
\end{array}\right.
$$

여기서 $T_{m}$ 은 bang-bang 제어에 적용된 토크이며, $t_{\text {off }}$ 는 양의 토크에서 음의 토크로 바뀌는 시간을
나타낸다. 식 (9)와 같은 bang-bang 제어를 적용하 면 조종을 통해 얻어지는 최종 각도는 다음과 같이 유도된다.

$$
\theta_{\text {final }}=T_{m} t_{\text {off }}^{2} / J_{t}
$$

식 (10)으로 나타나는 최종 각도식은 bang-bang 제어를 적용할 경우 추종제어와는 다르게 최종각도 도달을 위해 제어 입력의 크기와 지속 시간만이 필 요함을 말해준다. 따라서 유연체의 위치 제어를 간 단하게 할 수 있는 장점이 있다.

식 (9)를 단위계단 함수를 도입해 표현하면 다음 과 같이 쓸 수 있다.

$$
T_{h}=T_{m}\left[u(t)-2 u\left(t-t_{o f f}\right)+u\left(t-2 t_{o f f}\right)\right]
$$

여기서 $u(t)$ 는 단위계단함수를 나타낸다.

입력성형은 이와 같은 제어 입력에 다음 그림과 같은 임펄스를 기존의 조종 제어에 합성곱(convolution)하는 방법이다. 이 방법의 기본 개념은 첫 번째 임펄스에 의해 발생한 진동을 두 번째 임펄스 에 의한 진동으로 상쇄시키는 방법이다. 이 연구에 서 고려한 $\mathrm{ZV}$ (zero velocity) 입력성형기는 다음 그 림과 같다.

Fig. 2에 나타난 두 개의 임펄스의 높이와 시간 간격은 다음과 같이 주어진다 ${ }^{(8)}$.

$$
A_{1}=\frac{1}{1+K}, A_{2}=\frac{K}{1+K}, t_{2}=\frac{\pi}{\omega_{d}}
$$

여기서

$$
K=e^{-\pi \zeta / \sqrt{1-\zeta^{2}}}, \omega_{d}=\omega_{n} \sqrt{1-\zeta^{2}}
$$

이다. $\omega_{n}, \zeta$ 는 제어 대상 진동모드의 고유진동수와

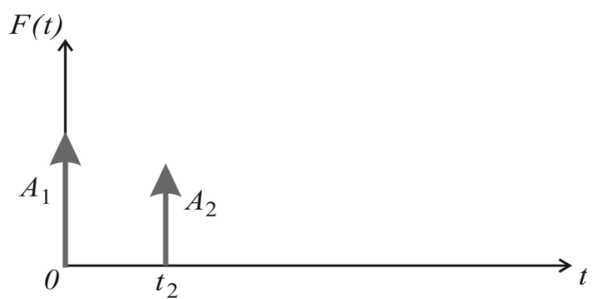

Fig. 2 ZV input shaper 
감쇠계수를 나타낸다. 입력성형기를 적용하기 위해 서는 먼저 조종으로 인해 유발되는 진동 모드의 진 동수와 감쇠계수를 구해야 한다.

Fig. 2로 주어지는 입력성형기는 다음 식으로 표 현된다.

$$
F(t)=A_{1} \delta(t)+A_{2} \delta\left(t-t_{2}\right)
$$

여기서 $\delta(t)$ 는 Dirac delta 함수이다. 입력성형은 조종을 위한 본래의 제어기에 입력성형기를 합성곱 함으로써 이루어진다. Bang-bang 조종 제어에 대한 식 (9)와 입력성형기인 식(14)를 합성곱하기 위해서 는 합성곱의 성질 중 다음을 이용한다.

$$
f(t) * \delta(t-T)=f(t-T) u(t-T)
$$

식 (15)를 이용하면 입력성형된 bang-bang 제어가 다음과 같이 유도된다.

$$
\begin{gathered}
\left(T_{h}\right)_{\text {input-shaped }}=T_{m}\left\{A_{1} u(t)+A_{2} u\left(t-t_{2}\right)\right. \\
-2\left[A_{1} u\left(t-t_{\text {off }}\right)+A_{2} u\left(t-t_{\text {off }}-t_{2}\right)\right] \\
\left.+A_{1} u\left(t-2 t_{\text {off }}\right)+A_{2} u\left(t-2 t_{\text {off }}-t_{2}\right)\right\}
\end{gathered}
$$

\section{Slewing 실험 장치}

이 연구의 이론 계산과 실험을 위하여 Fig. 3 에서 보이는 바와 같은 알루미늄 보 $(40 \times 1 \times 1000 \mathrm{~mm})$ 를 기어가 없는 $\mathrm{BLDC}$ 모터의 축에 연결하였다. BLDC 모터를 사용한 이유는 기어가 없기 때문에 회전을 방해하는 마찰력을 최소화할 수 있기 때문 이다. 우주 공간상에서 slewing하는 보는 마찰력이 없기 때문에 지상에서 로봇팔과 마찰력이 존재하는 시스템과 전혀 다른 형태의 동적 응답을 보여준다. 끝단의 집중질량은 자석을 이용해 $22 \mathrm{~g}$ 의 집중질량 을 구현하였다. 모터의 각도는 인코더를 이용해 계 측하고 보의 진동을 계측하기 위해 압전감지기를 부착하였다. 이와 같은 실험 장치를 운동방정식, 식 (7)을 이용해 수치 모사하기 위해서는 모터 로터의 질량관성모멘트 값과 보 고정부의 질량관성모멘트 값이 필요하다. 이론적으로 이 값을 추정하기 어렵 기 때문에 이 연구에서는 외팔보를 수직으로 위치 하고 보의 단진자 운동을 통해 허브 전체의 질량관
성모멘트 값을 추산하였다. Fig. 4는 보의 단진자 운 동 실험 결과를 보여준다. 이 그림으로부터 추산한 로터부의 질량 관성모멘트와 감쇠값은 $J_{h}=0.0014$ $\mathrm{kgm}^{2}, c_{h}=0.0177 \mathrm{~N} \cdot \mathrm{s} / \mathrm{rad}$ 이다. 그러나 허브의 감쇠 값은 수치계산에서 고려하지 않았다. 허브의 감쇠 값을 고려하면 bang-bang 제어에 의한 위치 제어 가 불가능하기 때문이다. 허브의 감쇠값은 실험에 서 음의 감쇠력을 이용해 상쇄하였다. 이를 통해 모터를 이용한 bang-bang 제어 실험 장치를 구현 하였다.

실험에서 모터 구동은 제어기의 $\mathrm{D} / \mathrm{A}$ 출력단 전 압이 모터 드라이버에 입력되고 모터 드라이버의 전류 출력으로 이루어지게 된다. 모터 드라이버의 출력은 드라이버의 이득으로 조종이 가능하기 때문 에 이론으로 그 관계식을 정확하게 추출해 내는 것 은 불가능하다. 이론 결과와의 비교를 통해 다음과

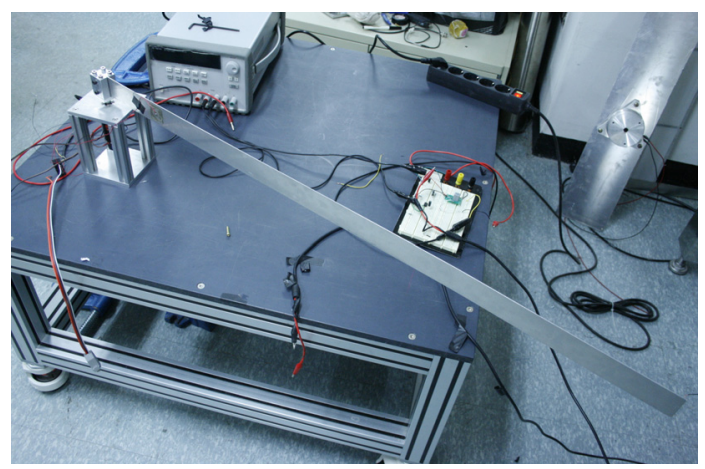

Fig. 3 Experimental setup for slewing beam

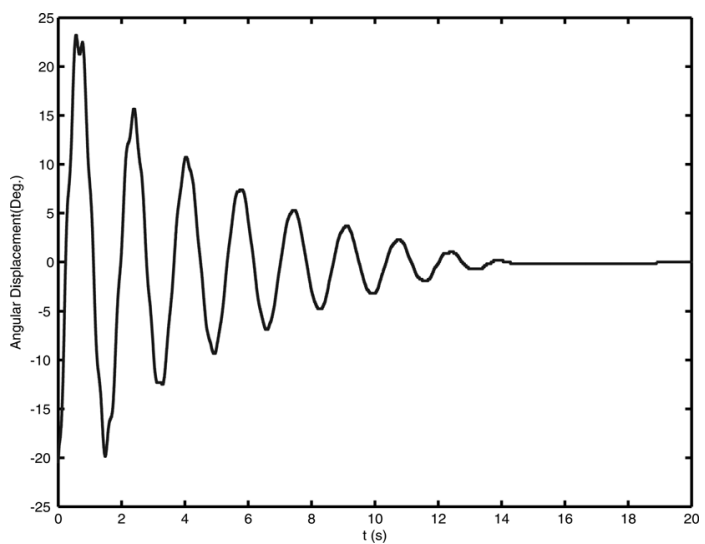

Fig. 4 Time history of angular displacement of motor shaft under pendulum motion 
같이 추정하였다.

$$
T_{h}=0.06 V_{c}
$$

여기서 $V_{c}$ 는 모터 드라이버에 인가되는 명령 전압 을 나타낸다.

\section{5. 수치 모사}

수치계산을 위해 사용한 허용함수는 균일 외팔보 의 고유진동 모드인데 다음과 같다.

$$
\phi_{i}(x)=\cosh \lambda_{i} x-\cos \lambda_{i} x-\sigma_{i}\left(\sinh \lambda_{i} x-\sin \lambda_{i} x\right)
$$

여기서 $\lambda_{i}=1.875,4.694,7.855,10.996, \ldots, \sigma_{i}=0.734$, $1.018,0.999,1.000, \ldots$ 이다. 식 (18)을 식 (4)와 (6)에 대입해 질량행렬, 강성행렬, 그리고 연성행렬을 계 산해 수치 모사에 사용하였다.

Fig. 5는 원래의 bang-bang 제어와 입력성형된 bang-bang 제어를 보여준다. Fig. 6은 이를 통해 얻 어지는 회전 각도를 나타내며, Fig. 7은 보의 끝단 에서의 변위를 나타낸다. 수치계산 결과에서 알 수 있듯이 입력성형을 통해 진동이 억제될 수 있 음을 보여준다. 또한 Fig. 6으로 부터 진동과 강체 각운동이 서로 연성되어 있음도 알 수 있다. 연성 된 시스템의 기본진동수는 $2.95 \mathrm{~Hz}$ 이다. Fig. 6으 로부터 이론적으로는 slewing시 기본진동모드만이 가진됨을 알 수 있다. 따라서 기본진동모드에 대 해서만 입력성형기를 설계해도 그 효과가 크게 나타난다.

\section{Slewing 실험}

이론 결과에서 입력성형된 bang-bang 제어를 유 연보의 회전에 적용하면 Fig. 6과 7에서 보이는 것 처럼 이론적으로는 조종 제어와 진동억제가 동시에 가능함을 알 수 있다. 그러나 실제로 가능한지에 대 한 연구가 필요한데 이 연구에서는 Fig. 3 에 보이는 바와 같이 알루미늄 보의 끝 단에 집중질량을 매달 고 회전축에 $\mathrm{BLDC}$ 모터를 연결한 실험장치를 구 성하였다. 이론상으로는 Fig. 5와 같은 bang-bang 제어를 무중력 상태의 보에 적용하였을 때 time-

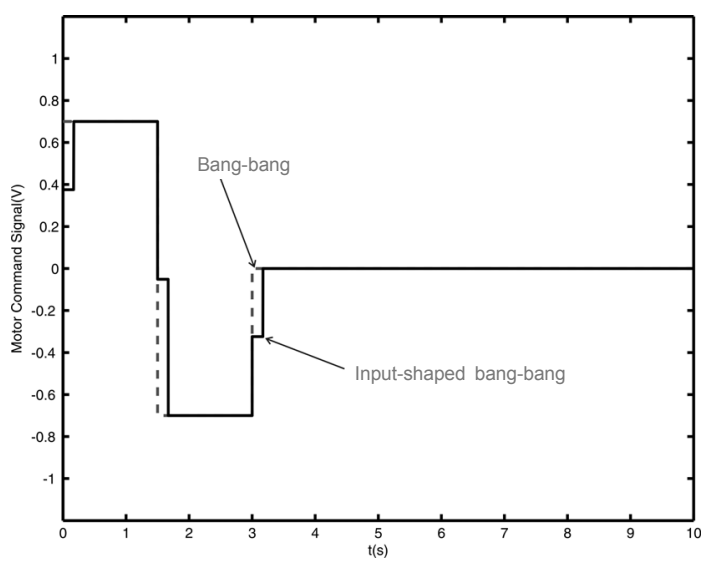

Fig. 5 Time history of bang-bang and input-shaped bang-bang torque

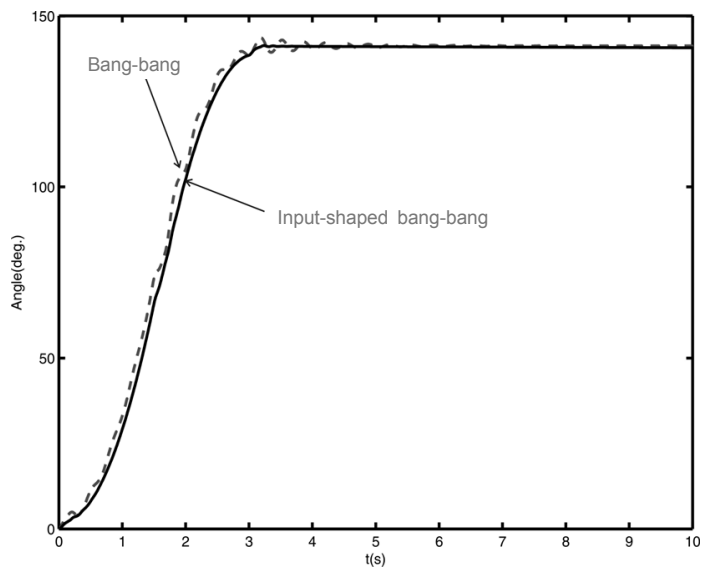

Fig. 6 Time history of hub angle

optimal 제어가 되며, 일정 각도에서 멈추게 되어 있다. 그러나 앞에서 설명한 바와 같이 실제 실험에 서 회전에 대한 저항이 존재하지 않도록 만드는 것 은 불가능하다. 따라서 이 연구에서는 엔코터의 각 도 입력값을 미분하고 적당한 값을 곱해 모터 제어 신호에 음의 감쇠력에 해당하는 신호를 적용해 실제 상황에서 발생하는 마찰 저항을 상쇄하는 방법을 개 발하여 적용하였다. Fig. 8은 이 연구에서 입력성형된 bang-bang 제어를 적용하기 위해 만든 simulink 블록 선도를 보여준다.

입력성형을 적용하기 위해 원래의 bang-bang 제어 에 의해 발생하는 보의 진동을 먼저 계측하였다. 실 험으로부터 계측된 보의 기본진동수는 $3 \mathrm{~Hz}$ 로 이론으 로 추정한 값과 거의 같다. Fig. 9는 계측된 진동수와 


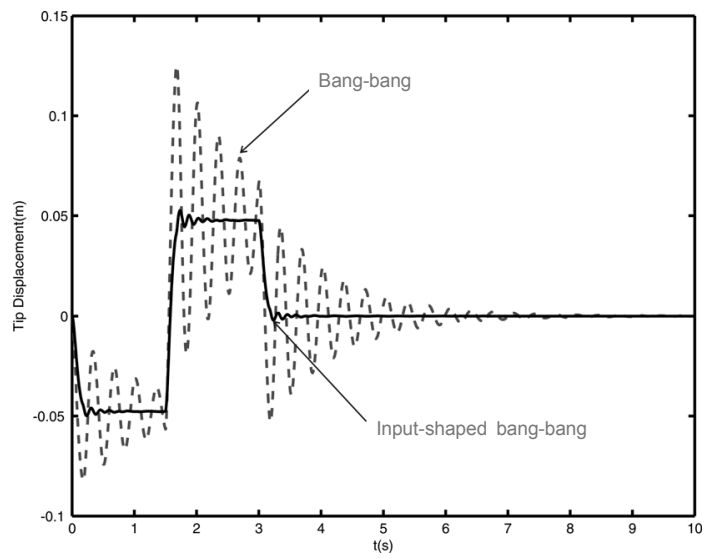

Fig. 7 Time history of tip displacement
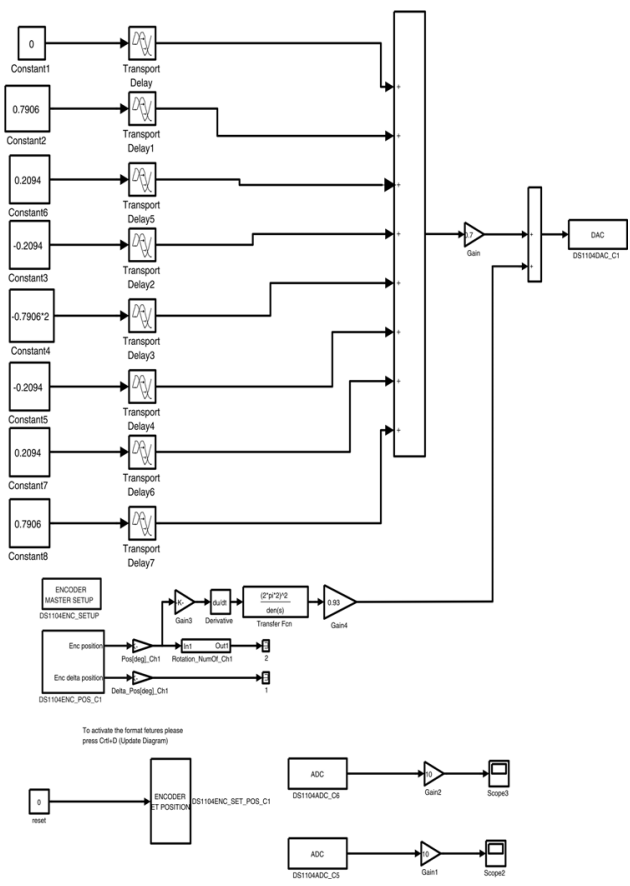

Fig. 8 Simulink block diagram for slewing experiment

감쇠계수를 이용해 입력성형된 bang-bang 제어 신 호를 보여준다. 실험에서 사용한 bang-bang 제어는 수치계산에 사용한 Fig. 5의 bang-bang 제어와 동일 하다. 그러나 입력성형된 bang-bang 제어는 약간 다른데 그 이유는 수치계산에서 추산한 감쇠계수보 다 실제 시스템의 감쇠계수가 크기 때문이다. 이로 인해 입력성형시 첫 번째 임펄스의 크기가 두 번째 보다 크게 나타난다.

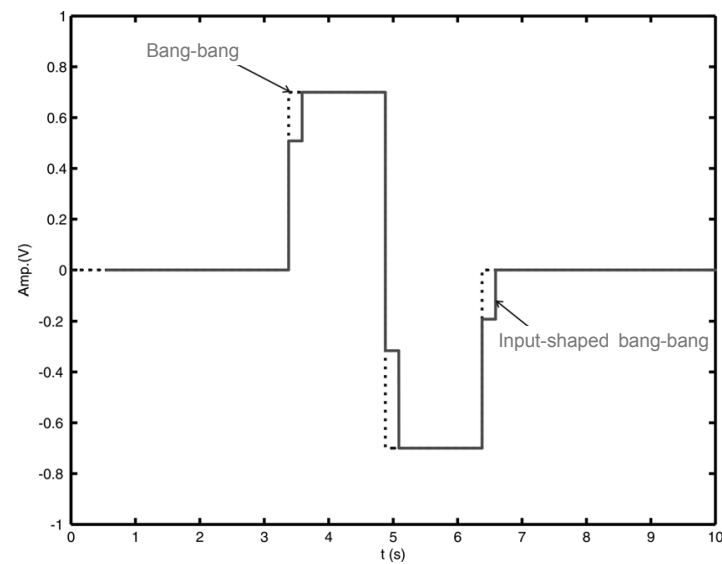

Fig. 9 Bang-bang control input to motor

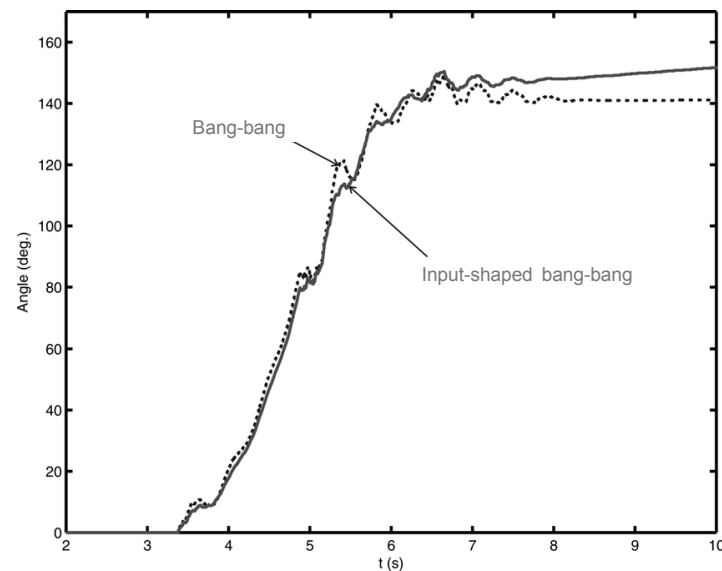

Fig. 10 Time history of angular displacement of motor shaft

Fig. 10은 원래의 bang-bang 제어와 입력성형된 bang-bang 제어에 의한 회전 각도를 보여준다. Fig. 6 의 수치계산 결과와 비교했을 때 최종 각도가 거 의 같음을 알 수 있다. 단, 진동과의 연성 효과는 실험에서 더 크게 나타남을 알 수 있는데 수치계산 에 사용한 모터의 질량 관성모멘트가 영향을 준 것 으로 사료된다. 모터의 질량 관성모멘트가 클 경우 보의 진동이 모터 허브의 각운동을 유발하기 어렵 기 때문에 연성 효과는 작아진다. Fig. 10 은 가상의 음의 감쇠력을 적용하는 경우 모터와 보를 이용한 slewing 실험에서 bang-bang 조종 제어에 의한 위 치 제어가 구현될 수 있음을 보여준다. 그러나 모터 의 마찰력을 완벽하게 상쇄할 수 없기 때문에 최종 위치는 약간씩 차이가 나게 된다. 


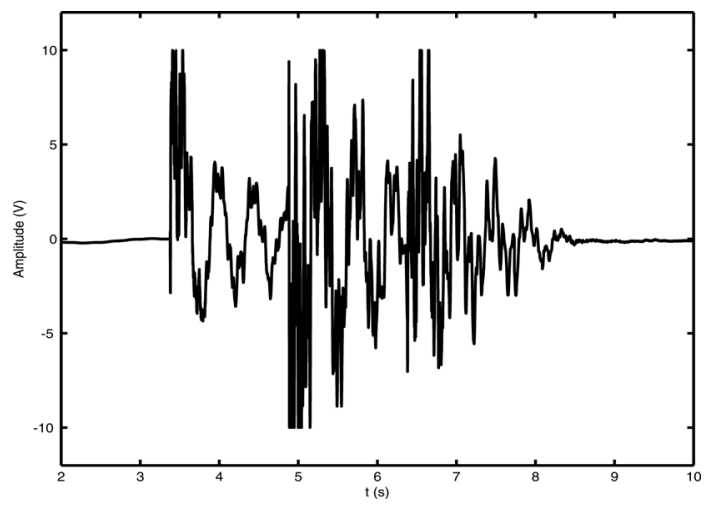

(a) Bang-bang slewing

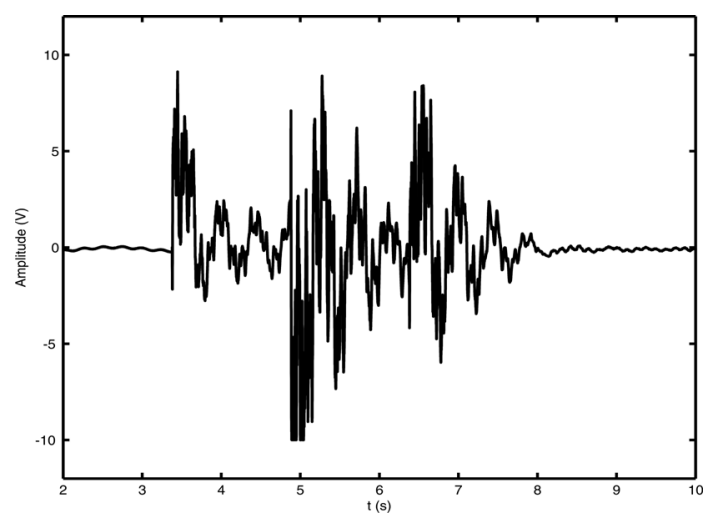

(b) Input-shaped bang-bang slewing

Fig. 11 Time response of PZT sensor output

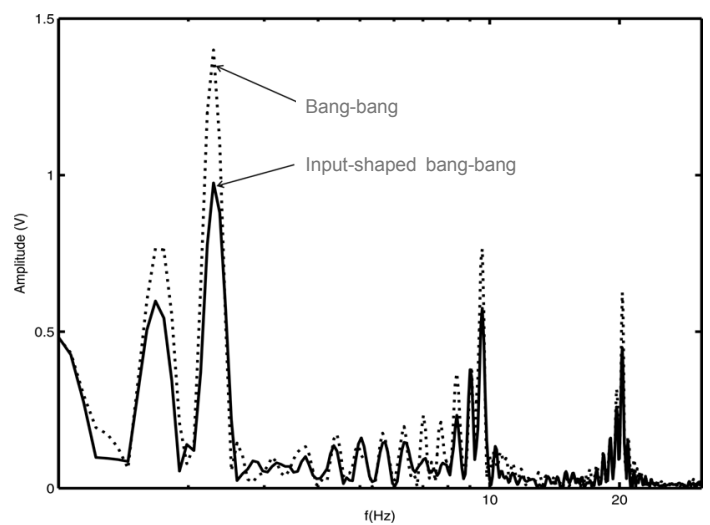

Fig. 12 Power spectral density curve for PZT sensor output

Fig. 11(a)는 bang-bang 조종 제어만을 적용할 경 우의 PZT 센서의 출력신호이며, Fig. 11(b)는 입력 성형된 bang-bang 조종제어를 입역하였을 경우의 PZT 센서의 출력신호이다. Fig. 11의 결과 차이를
확인하기 위해 Fig. 12와 같이 각 신호에 대한 power spectral density curve를 구해 비교하였다. Fig. 12 로 부터 입력성형된 bang-bang을 적용할 경우 진동 을 억제시킬 수 있음을 알 수 있다.

그러나 Fig. 11에서 나타나는 PZT 센서의 출력 신호는 이론 계산 결과인 Fig. 7에서 나타나는 끝 단의 변위와는 다름을 보여준다. 먼저 bang-bang 제어의 특성으로 인해 나타나는 정적 변위가 Fig. 11 에는 보이지 않는다. 이는 PZT 센서의 압전 특 성으로 인해 정적 변위로 인한 변형이 더 이상 전 하를 발생시키지 못하기 때문이다. 즉, PZT 센서 는 $\mathrm{AC}$ 성분만 계측할 수 있기 때문이다. 또한 Fig. 7에는 오직 기본 모드만이 현저하게 나타나는 반면에 Fig. 11에는 여러 진동 모드가 나타난다. 이 는 모터 구동으로 인해 다양한 진동 모드가 가진 되는 것으로 추정되었다. 이와 같이 실제 시스템에 서 발생할 수 있는 다양한 진동을 억제하기 위해 서는 입력성형된 조종 제어만으로는 부족함을 알 수 있다. 이런 진동을 억제하기 위해서는 차후 압 전작동기로 보강된 추가의 진동제어력이 필요할 것으로 예상된다.

\section{7. 결 론}

이 연구를 통해 다음과 같은 결론이 도출되었다.

(1) 유연보의 회전 동적 모델을 통해 관성적인 연성 효과로 인해 조종 제어시 진동이 유발된다.

(2) 이 연구에서 제안한 음의 감쇠력을 이용한 마찰력 제거 알고리듬을 이용하면 우주 공간상의 유연 구조물의 회전을 실험을 통해 묘사할 수 있다.

(3) 입력성형된 조종 제어를 통해 경량 유연 구 조물에 발생하는 진동을 억제할 수 있다.

(4) 실제 실험을 통해 입력성형된 조종 제어만으 로는 완벽한 진동 제어를 기대할 수 없음을 확인하 였다. 따라서 추가적인 능동진동제어 방법의 도입이 필요하다.

\section{후 기}

이 연구는 한국연구재단의 “유연 다물체 지능구 조물의 동적 모델링 및 능동진동제어"과제의 일환 으로 수행되었습니다. 


\section{참 고 문 헌}

(1) Garcia, E. and Inman, D. J., 1991, Modeling of the Slewing Control of a Flexible Structure, Journal of Guidance and Control, Vol. 14, No. 4, pp. 736 742.

(2) Denoyer, K. K. and Kwak, M. K., 1996, Dynamic Modeling and Vibration Suppression of a Slewing Structure Utilizing Piezoelectric Sensors and Actuators, Journal of Sound and Vibration, Vol. 189, No. 1, pp. 13 31.

(3) Kwak, M. K. and Nam, S. H., 2001, A Study on the Valid Dynamic Modeling for the Slewing and Vibration Suppression Control of Beam, Transactions of the Korean Society for Noise and Vibration Engineering. Vol. 11, No. 2, pp. 292 300.

(4) Singhose, W. E., Banerjee, A. K. and Seering,
W., 1997, Slewing Flexible Spacecraft with Deflectionlimiting Input Shaping, Journal of Guidance, Control, and Dynamics, Vol. 21, No. 2, pp. 264 270.

(5) Gorinevsky, D. and Vukovich, G., 1998, Nonlinear Input Shaping Control of Flexible Spacecraft Reorientation Maneuver, Journal of Guidance, Control, and Dynamics, Vol. 21, No. 2, pp. 264 270.

(6) Yoo, H. H., Ryan, R. R. and Scott, R. A., 1995, Dynamics of Flexible Beams Undergoing Overall Motions, Journal of Sound and Vibration, Vol. 181, No. 2, pp. 261 278.

(7) Yun, S.-H., 2006, Formulations of Linear and Nonlinear Finite Element for Dynamic Flexible Beam, Journal of the Korean Society of Precision Engineering, Vol. 23, No. 2, pp. 113 121.

(8) Rusu, M. S., Grama, L. and Morar, A., 2009, Acta Electrotehnica, Vol. 50, No. 2, pp. 159 164. 